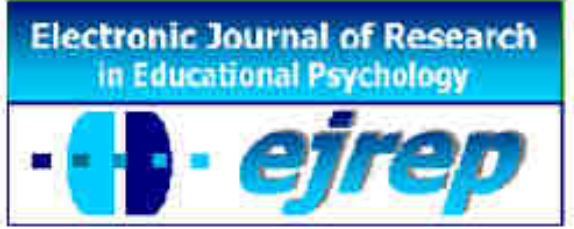

\title{
Students' motivation to learn in middle school - a self-regulated learning approach
}

\section{Paula Paulino ${ }^{1}$, Isabel Sá ${ }^{2}$ \& Adelina Lopes da Silva ${ }^{3}$}

\author{
${ }^{1}$ Assistant Professor at Lusófona University, Lisbon. Member of Re- \\ search Center for Psychological Science, Faculty of Psychology, Univer- \\ sity of Lisbon \\ ${ }^{2}$ Researcher, Member of Research Center for Psychological Science, \\ University of Lisbon; Faculty of Psychology, University of Lisbon \\ ${ }^{3}$ Emeriti Full Professor, Member of Research Center for Psychological \\ Science, Faculty of Psychology, University of Lisbon
}

\section{Portugal}

Correspondence: Paula Paulino. Lusófona University, Campo Grande, 376, 1749-024 Lisbon, Portugal/Faculty of Psychology, University of Lisbon, Alameda da Universidade, 1649-013 Lisbon, Portugal. Email: a.paula.paulino@gmail.com; anapaulapaulino@campus.ul.pt

(C) Education \& Psychology I+D+i and Ilustre Colegio Oficial de la Psicología de Andalucía Oriental (Spain) 


\section{Abstract}

Introduction. The self-regulation of motivation (SRM) is conceptualized as a metamotivational process that guides students' efforts and persistence when performing tasks. This process regulates students' behavior through strategies that are influenced by motivational beliefs. SRM allows students to motivate themselves and guides their behavior.

Method. In this article we aim to analyze and identify factors that may contribute to students' motivation to learn. The Self-Regulation of Motivation for Learning Scales (SRMLS) is an inventory developed to assess the SRM process in two major dimensions: motivational beliefs and SRM strategies. In order to achieve our goals 550 students from 7 th to 9 th grades responded to SRMLS.

Results. Self-efficacy expectations, task value and achievement goals are good predictors of self-regulation of motivation strategies.

Conclusion. Results suggest that self-efficacy expectations, task value and achievement goals may be important in promoting student's regulation of motivation for learning. Also, data analyses support the Self-Regulation of Motivation for Learning Scales' construct and concurrent validities for use with this population. Future implications for research and education are discussed.

Keywords. Self-regulated learning, regulation of motivation, achievement goals, selfefficacy, task value, motivational regulation strategies, students. 


\section{Motivación para el aprendizaje en alumnado de Enseñanzas Medias: un enfoque de aprendizaje autorregulado}

\section{Resumen}

Introducción. La autorregulación de la motivación (SRM) se conceptualiza como un proceso de meta-motivación que guía los esfuerzos y la persistencia de los alumnos al realizar las tareas. Este proceso regula el comportamiento de los estudiantes a través de estrategias que son influenciados por las creencias motivacionales. SRM permite a los estudiantes se motivan y guía su comportamiento.

Método. En este artículo nos proponemos analizar e identificar los factores que pueden contribuir para la motivación para el aprendizaje. La Escala de autorregulación de la motivación para el aprendizaje (SRMLS) es un inventario desarrollado para evaluar el proceso de SRM en dos dimensiones principales: creencias motivacionales y estrategias de SRM. Con el fin de lograr nuestros objetivos 550 estudiantes del 7 al 9 grado respondieron a SRMLS.

Resultados. Expectativas de autoeficacia, valor de la tarea y las metas de logro son buenos predictores de la autorregulación de las estrategias de motivación.

Conclusión. Los resultados sugieren que las expectativas de autoeficacia, valor de la tarea y las metas de logro pueden ser importantes en la promoción del alumno regulación de la motivación para el aprendizaje. Además, los datos apoyan la validez de constructo e la validez concurrente del instrumiento para su uso con esta población. Se discuten las implicaciones futuras para la investigación y la educación.

Palabras Clave: Aprendizaje autorregulado, regulación de la motivación, metas de logro, auto-eficacia, valor de la tarea, estrategias de regulación motivacional, estudiantes. 


\section{Introduction}

Educational psychology research highlights the importance of self-regulated learning skills (SRL) for successful learning (e.g., Lopes da Silva, Veiga Simão \& Sá, 2004; Montalvo \& González-Torres, 2004; Pintrich, 2003; Zimmerman \& Schunk, 2001). While students' competence to manage metacognitive components has been the subject of several studies in the past, the competence to regulate school motivation has not received the same attention from research on learning and performance (Authors, 2012; Wolters, 2003, 2011). However, students' lack of motivation and self-regulation to learn seem to be critical issues which need to be addressed (Authors, 2011; Wolters, 2003; Zimmerman, 2008).

Several authors have claimed for a better understanding of how students can monitor, control, and regulate their own motivation (e.g., Boekaerts \& Corno, 2005; Wolters, Benzon, $\&$ Arroyo-Giner, 2011). Self-regulation of motivation (SRM) has been regarded as a key concept in the field of self-regulated learning (Wolters, 2003). Specifically, SRM concerns students' acts to maintain motivation and persistence in school tasks, presuming students' intentional action, and competency to self-motivate. More specifically, SRM can be described as the actions through which individuals intentionally initiate, maintain or increase their level of motivation to engage in a given task, complete it and/or reach a goal.

This form of regulation is achieved by a deliberate intervention in the management and control of the processes that affect motivation. It involves thoughts and behaviors that influence students' choices, efforts, and persistence in school tasks (Wolters, 2003; Wolters \& Rosenthal, 2000). Therefore, it constitutes a motivational dimension of the self-regulation of learning process, as it explores the processes that encourage students to regulate their own motivation (Zimmerman \& Schunk, 2008). As such, it becomes necessary to identify the strategies students use to regulate their own motivation and what influences their use (Authors, 2011; Wolters, 2003).

An effective use of a motivational strategy implies an increased self-knowledge about a desired goal, the tasks' interest, the utility that has been proven in previous uses and the strategies to adopt in given situations. According to Wolters (2011), students' regulation of motivation depends on their metalevel knowledge about motivation. This knowledge might include information concerning students' current level of motivation, the processes that im- 
pact their motivation, and the factors that may affect motivation. Specifically, it includes the motives that guide students on the regulation of their motivation, and the strategies they believe to be effective along the process. Although the use of such strategies might reflect more directly an effort to manage motivation, they are also dependent on students' metamotivational knowledge, and the ways they consider to be effective to regulate it (Wolters \& Benzon, 2010). Metalevel knowledge about motivation is essential when considering which motivational regulation strategies are more effective within a particular task, or when deciding on how to appropriately adapt a strategy to a specific situation.

Many studies on the regulation of motivation have focused on students's strategic behavior, and strategy use (e.g., Wolters \& Benzon, 2010; Wolters \& Rosenthal, 2000). Results indicated that strategies may influence both the shape and quality of information processing, and the selection and use of different learning strategies (Montalvo \& Torres, 2004).

In the present study, it is assumed that the regulation of motivation requires an intentional participation of the student on the selection of specific strategies and their effective use. Therefore, it becomes essential to study self-variables such as expectancies, values, and goals that can determine the use of particular strategies. Such variables have been described as motivational beliefs. Moreover, motivational beliefs involve students 'opinions, values, and judgments used to assign meaning to learning events. Concurrently, motivational beliefs may refer to the value students attribute to a domain, to their expectations about the efficiency of learning, to teaching strategies, or to self-efficacy beliefs. Overall, such beliefs act as a framework that guides students' thoughts, feelings, and behaviors in a particular area (Boekaerts, 2002). Following this theoretical framework, the current study was designed to examine the relationship among students' knowledge about effective motivational regulation strategies and their motivational beliefs.

Several studies have found students' expectancies about their achievement on specific tasks, and the reasons for completing the latter, might influence the use of particular selfregulated learning strategies (e.g., Eccles \& Wigfield, 2002; Dweck \& Master, 2007; Pajares, 2007; Sansone \& Thoman, 2005; Wolters, 1999; Wolters \& Benzon, 2010; Wolters \& Rosenthal, 2000; Zimmerman \& Martinez-Pons, 1990). Self-efficacy, task value, and achievement 
goals have been proved to be determinants of self-regulated learning strategies use, and of motivational regulation strategies as well (Sansone, Wiebe, \& Morgan, 1999; Wolters, 1998; Wolters \& Benzon, 2010; Wolters \& Rosenthal, 2000; Zimmerman \& Martinez-Pons, 1990).

Consistent with these findings, the focus of our research was to analyse and identify self variables that may contribute to students' motivation to learn. Hence, we developed a questionnaire to assess components of students' achievement motivation, namely, selfefficacy, achievement goals and task value (Authors, in press-a). Wolters $(1998,2003)$ identified different types of strategies through which students can regulate their motivation. These strategies include attempts to regulate different motivational beliefs that have been discussed in the literature of achievement motivation, such as achievement goals, self-efficacy, and task value (Wolters \& Benzon, 2010).

\section{Self-regulatory Processes within a Motivational Dimension of Self-Regulated Learning}

Task value. Interest and perception of school value are two indicators that have been found to determine students' motivation (Eccles \& Wigfield, 2002). Following Eccles's expectancy-value theory (e.g., Eccles, 2009; Eccles \& Wigfield, 2002, Wigfield \& Eccles, 2000), motivation varies according to the value that is assigned to the goal we want to achieve, and to our expectation of accomplishment. Moreover, Wolters and Rosenthal (2000) stated that when students are convinced that their learning task is important, interesting, and useful, they are more willing to make an effort and persist longer towards finishing the task. Students must consider school tasks as valuable for the achievement of personal plans, otherwise, their motivation to engage in a process of self-regulated learning will most likely decrease. There are several hypotheses as to why students perceive schools to be worthless for their future, including low perceptions of personal competence that may influence educational aspirations (Brickman \& Miller, 2001). Another common problem relates to gaps in the establishment of personal goals that strengthen students' relationship with schools.

Achievement goals. Several theories of achievement motivation have claimed that students formulate personal goals that guide their performance in school (achievement goals). Goal theory assumes that individuals can pursue multiple pathways to achieve similar goals or outcomes, and that there may be multiple goals, often interacting reciprocally (Eccles \& Wig- 
field, 2002). Furthermore, two different kinds of achievement goals have been considered, namely mastery goals and performance goals. Each one has been associated with a distinct pattern of performance (e.g., Dweck \& Master, 2007), and with different motivational behaviors, such as approaching or avoiding tasks (Fryer \& Elliot, 2007). Mastery goals are related to the learning process and the challenge for gaining expertise, whereas performance goals are associated with ego orientations, seeking and maintaining a positive image of one's self, skills and self-worth. Some authors have suggested the distinction between performance-approach and performance-avoidance goals (Elliott \& Church 1997; Midgley et al., 2000). According to this perspective, performance-approach goals imply engagement in achievement tasks for performance reasons, whereas performance-avoidance goals concern disengagement in order to avoid being considered less intelligent (Eccles \& Wigfield, 2002).

Self-efficacy expectations. Along with task value, self-efficacy beliefs seem to be essential for students' motivation for learning. More specifically, the beliefs that people have about their abilities and the consequences of their efforts determine the cognitive processes, aside from motivational and emotional functioning. These beliefs appear to be key elements for stimulating the processes of self-regulated learning (Bandura, 1986; Boekaerts, 2002; Wolters, 2003). So to understand achievement motivation, it is essential to consider variables which are associated with the self -namely how students project themselves in the future through goals, beliefs about own skills, and the value attributed to school tasks (Alderman, 2004; Pintrich,1999; Wolters \& Rosenthal, 2000; Zimmerman, 2008, 2011; Zimmerman \& Bandura, 1994). From a cognitive perspective, motivation is the internal circumstance that both encourages and focuses on goal-oriented behavior, thus cognitive determinants of motivation must be considered (Schunk, 2004; Zimmerman \& Schunk, 2008). Nonetheless, it is crucial to understand how these variables are conceptually related with each other and with the self-regulation of motivation strategies.

There are both empirical and theoretical evidence to believe that students' motivational beliefs may be important to understand their use of distinct motivational regulation strategies. However, the relation between students' task value, self-efficacy and goal orientations, and their use of motivational regulation strategies remains relatively unexplored (Authors, in press-a, b; Wolters \& Benzon, 2010; Wolters \& Rosenthal, 2000). In light of this, Wolters 
(2003, 2011) has argued that more work is needed on how the links between expectancies, goals, values, performance and choice change across time and schooling.

There is strong and recent evidence that performance-avoidance and performanceapproach goals are highly correlated (e.g., Bong, 2009; Bong, Woo, \& Shin, 2013; Murayama, Elliot, \& Yamagata, 2011). Also, the task's importance, interest and utility have correlated strongly with each other and with self-efficacy expectations (e.g., Lee, Bong, \& Kim, 2014; Hulleman, Durik, Schweigert, \& Harackiewicz, 2008). Finally, studies have indicated positive correlations between task value, self-efficacy expectations and achievement goals (Authors, in press-a, b; Wolters \& Benzon, 2010; Wolters \& Rosenthal, 2000).

On this basis, and given the close association between these concepts, one may consider the existence of a global motivation orientation for learning, combining achievement goals, self-efficacy expectations, and task value beliefs. Finding this global orientation may have particular interest for researchers and teachers, as it provides information about key determinants to students' motivation, which can guide teaching practices. Therefore, the present study describes the confirmatory factorial study of two self-report scales developed to assess the process of self-regulation of motivation, including motivational beliefs and SRM strategies. With such analysis, we expect to clarify the relationship between motivational beliefs, such as self-efficacy expectations, task value and achievement goals, and the willingness to use self-regulation strategies.

Motivational regulation strategies. One way to regulate achievement motivation is by emphasizing a particular goal or reason for wanting to complete the school task. Wolters (1998) found that students tend to face the various motivational problems by thinking about or stressing to themselves the reasons they had for wanting to complete the task successfully. This form of regulation is related to achievement goal theory and consists for example, of students' attempts to emphasize their desire to get good grades or to do well in class. Moreover, students reported that this kind of thinking would help them overcome the motivational problems to complete their work. Another way of promoting motivation was to remind themselves of wanting to learn as much as possible or become better at what they were learning as a way of persisting in the task (Wolters, 1998). 
A more intrinsic way to regulate motivation was suggested by Sansone and colleagues (Sansone et al., 1992; Sansone et al., 1999), when they argued that interest enhancement strategies were related to students' work to increase effort or time spent on tasks, by making the activity more enjoyable or more interesting to complete at that exact moment. For example, Xu and Corno (1998) and Wolters (1998) found that third grade and college students used this type of strategy to increase their effort in school tasks.

Several studies have found that students reported the use of self-consequating strategies, such as establishing and providing extrinsic consequences for assorted aspects of their engagement in learning activities (e.g., promising a reward such as going to cinema when completing homework) (Purdie \& Hattie, 1996; Zimmerman \& Martinez-Pons, 1990; Wolters, 1998). Another type of motivational regulation strategies is environmental control. Wolters (1998) found evidence that when faced with particular difficult or boring tasks, students would study in selected environments, or only after taking naps, as an effort to ensure that they would be alert while trying to work.

In a study about the structure of self-regulated academic motivation among college students, and through structural equation modeling, Gonzalez, and colleagues (2005) reported that the regulation of motivation is a multidimensional construct. Their findings suggest that in any given situation, students may choose from a range of strategies to regulate their motivation. Results also suggested that the regulation of motivation was strongly associated with higher academic achievement, particularly through the use of performance extrinsic self-talk (Gonzalez et al., 2005).

In another research with college students Wolters and Benzon (2010) used a selfreport scale and found that students did not use all of these regulatory strategies equally. For example, students reported using strategies to increase their focus on performance goals or to manage their environment more frequently than strategies to sustain their motivation through more intrinsic forms of motivation, such as the regulation of mastery goals.

The present study aimed to further study self-regulation of motivation process, namely the determinants of self-regulation of motivation strategies. Therefore, our goal was to identify 
beliefs regarding motivation to learn, more specifically those that promote students' use of self-regulation of motivation strategies. Two newly developed scales for evaluating SRM, namely the Self- Regulation of Motivation for Learning Scales (SRMLS) (Authors, in pressa) were used. Validity and reliability analyses were conducted as we want to understand whether SRMLS constitutes a valid and reliable measure for the three types of motivational beliefs (self-efficacy, task value, and achievement goals), and for the five types of motivational regulation strategies (mastery self-talk, situational interest enhancement, selfconsequating, environmental structuring, and performance self-talk). Also, such a measure might ascertain whether different dimensions concerning beliefs and strategies are related to each other, and in which ways.

\section{The aims}

Our aim was to understand how self-efficacy expectations, task value and achievement goals are related and how they correlate with the use of strategies to self-regulate one's motivation. Thus, we conducted a study with SRMLS also to improve measurement accuracy, while increasing the sample size. To test the SRMLS validity, construct validity and concurrent validity we aimed to: a) determine whether and how different dimensions of the SRAM are related to each other; b) analyze the structure of SRMLS, particularly whether it may reflect multi-dimensional constructs, with a confirmatory factorial analysis; c) determine the overall psychometric properties of the instrument, with specific reference to its reliability and concurrent validity.

\section{Method}

\section{Participants}

The sample was composed of 550 students from two public schools, 259 boys (47.3\%) and 289 girls (52.7\%), with ages between 12 and 18 years $(M=13.19 ; \mathrm{SD}=1.16)$. The distribution of the sample was as follows: 7th grade, $n=261 ; 8$ thgrade, $n=162$; and 9th grade, $\mathrm{n}=121$. The majority of the students had no grade retentions $(76.7 \%), 14.2 \%$ had one grade retention and $8.4 \%$ had two or more retentions. Because sample sizes are important in factor analysis, participants were recruited by taking into account literature considerations on this topic (e.g., Hoelter's critical N, participants to variable ratio 10:1) (Byrne, 2010). 


\section{Instruments}

Self-Regulation of Motivation for Learning Scales (SRMLS). Following exploratory factor analysis conducted elsewhere (for details see Authors, in press-a), the current study expands upon this research by describing a confirmatory factor analysis of the SelfRegulation of Motivation for Learning Scales (SRMLS). This instrument is an inventory composed of 38 items divided into two self-report scales developed to assess the selfregulation of motivation process in two major dimensions: motivational beliefs and SRM strategies (Authors, in press-a). The motivational beliefs scale is composed of the following dimensions: a) self- efficacy beliefs (eg, "I think I'm able to learn school content."); b) achievement goals (eg, "I prefer subjets that I like, even if they are harder."/"It motivates me to think that I can get better grades than my colleagues"/ "Having bad grades worries me") c) task value (e.g., "Subjets that I learn in school will be useful in my future studies. "/ "It is very important for me to do school work."). The following statement introduced the strategies dimension: "When I'm studying or doing school tasks and I find it difficult to continue......". This scale consists of the following subscales: a) regulation of learning goals (e.g., “... I tell myself that I must study to learn as much as I can."); b) regulation of value (e.g. "...I try to see the usefulness of the content/tasks for my life."); c) regulation of situational interest (e.g., “... to make studying more enjoyable, I try to focus on a fun aspect it might have."); d) regulation of performance goals (e.g., " ... I think that if I do not study my grades will get worse."); e) self-consequating (e.g., "I say to myself that if I finish this task I can do something that I like later."); f) environmental control (e.g. "I try to have no distractions around me."). Students rated how frequently they thought about or did the several statements presented on a 5point Likert scale (1 Never to 5 Always).

Other measures. In order to test the concurrent validity of the instrument, two other instruments were used: the Portuguese adaptation (Paixão \& Borges, 2005) of the revised Personal Achievement Goal Orientations of the Patterns of Adaptive Learning Scales (PALS) (Midgley et. al, 2000) and the Portuguese adaptation (Teixeira, 2008) of the Multidimensional Scale of Perceived Self-Efficacy (MSPE) (Bandura, 1990). 
The PALS was developed according to the goal orientation theory to examine the relation between the learning environment and students' motivation, affect, and behavior. For this purpose we used the student scale to assess personal achievement goal orientations. The Portuguese adaptation has 14 items divided into: a) mastery goals (five items) ( $\alpha=.87)$; b) performance approach goals (five items) $(\alpha=.87$ ), and c) performance avoidance goals (four items) $(\alpha=.75)$. Participants responded to all items on a 5-point Likert scale ranging from 1 (Not all True) to 5 (Very True) (Paixão \& Borges, 2005).

The MSPE is a self-report measure of perceived self-efficacy developed by Bandura (1990) composed by nine scales. In this study only the self-efficacy for academic success scale was used. For each of the 11 items $(\alpha=.76)$ respondents are asked to rate their level of capability on a 5-point scale, from 1 (Very Difficult) to 5 (Very Easy) in performing any given activity (Teixeira, 2008).

\section{Procedure}

The application was collective during the daily school schedule and participants were told that their cooperation was voluntary and anonymous. The participants were informed that our interest was to understand how they thought about school. They were then asked to indicate how much they agreed with the statements presented on a five-point scale. As the participants were underage, parents' and carers' consent was obtained. The scales had the prior approval of the Ministry of Education and were in line with the rules of the host institution of the undergoing investigation. Data was collected between October 2012 and December 2012.

\section{Data Analysis}

Descriptive statistics, item analysis, content validity, reliability analysis and exploratory factor analysis were conducted using the statistical software package SPSS 20. AMOS 20 was used to perform the confirmatory factor analysis to determine the factor structure of the scales. Item analysis included a missing value test, which revealed missing data represents less than $5 \%$ of the total sample. This diagnostic information indicates that students' nonresponse to items is not missing at random (Bennet, 2001; Schafer, 1999). 
Additional data screening indicated the presence of outliers; however, after performing a variety of summary descriptive statistics (e.g., dispersion, skewness and kurtosis) it was decided not to exclude outliers because data normality assumption was not violated.

In order to explore self-variables that might predict students `motivation and study the overall characteristics of the instrument, results are presented into three sections: (1) exploratory factor analysis of SRMLS; (2) descriptive and bivariate analyses for all the major variables included in the study; (3) confirmatory factor analysis showing the internal structure of the items measuring motivation beliefs and strategies; and (4) concurrent validity analysis.

\section{Results}

\section{Exploratory factor analysis}

We first conducted an exploratory factor analysis (EFA) of the SRMLS using varimax rotation with Kaiser normalization and maximum likelihood estimation. Items with factor loadings equal to (or less than) .40, as well as those with loadings discriminating in more than one component, were removed from the analysis.

For the motivational beliefs scale a four-factor structure was extracted, accounting for approximately $59 \%$ of the total variance. These four factors correspond to: a) performanceapproach goals (four items) $(\alpha=.81)$, b) self-efficacy (four items) $(\alpha=.71)$, c) task valueutility ( $\alpha=.76)$ (three items), and d) performance-avoidance goals $(\alpha=.65)$ (three items). Cronbach's alpha was calculated for each factor as an indicator of internal consistency reliability and the majority of the factors revealed good values (above .70) (Field, 2009). Only the fourth factor had a slightly lower internal consistency $(\alpha=.65)$. However, considering that this instrument is mainly for research, the subscale has only three items and is being applied for the first time, we decided to maintain this sub-area (Hill \& Hill, 2009). Bartlett's test of sphericity $(2189.176 ; 105 \mathrm{df}, p<0.0001)$ and Kaiser-Meyer-Olkin index $(\mathrm{KMO}=.784)$ showed acceptable results.

The structure of the regulation of motivation strategies scale also revealed a fourfactor solution, which accounted for approximately $65 \%$ of the total variance. The factors 
correspond to: a) regulation of value and mastery goals (five items) $(\alpha=.79)$, b) selfconsequating (three items) $(\alpha=.74), \mathrm{c})$ regulation of situational interest (three items) $(\alpha=$ $.71)$, and d) regulation of performance-avoidance goals (two items) $(\alpha=.78)$. Bartlett's test of sphericity $(2308.962 ; 78 \mathrm{df}, p<0.0001)$ and Kaiser-Meyer-Olkin index $(\mathrm{KMO}=.816)$ showed adequate results.

EFA extracted a theoretical coherent solution regarding students' different motivational beliefs and regulation strategies, indicating good content validity. SRMLS scales were formed from the means of the items of each factor, which were used in subsequent analyses. Similar structural results were previously obtained elsewhere [for further discussion, see Authors (in press-a)].

\section{Descriptive and bivariate analysis}

Motivational beliefs. Post hoc comparisons using the Tukey HSD test indicated significant differences in how often each type of motivational belief was reported $\left[\mathrm{F}(1,549)=220.45, p^{<} .001, \eta^{2}=.29, \pi=1.00\right]$. The highest mean value corresponded to task value - utility $(M=4.20, S D=0.71)$ and the factor with the lowest mean was performanceapproach goals $(M=3.25, S D=0.98)($ Table 1$)$.

The values obtained from correlations between factors indicated weak correlations $(.23 \leq r$ $\leq .29)$ revealing sensibility of the instrument to various areas within the conceptual field of motivational beliefs (Field, 2009). Table 1 shows that the factors were all correlated, with higher correlations between factor 2 and 3, more specifically, items that assess beliefs regarding self-efficacy and task value $(r=.29, p \leq .01)$ and lower correlations between factors 2 and 4 , self-efficacy and performance-avoidance goals $(r=.23, p \leq .01)$. 
Table 1. Descriptive statistics and bivariate correlations for variables in the study

\begin{tabular}{|c|c|c|c|c|c|c|c|c|c|c|c|c|}
\hline & M & SD & $\begin{array}{l}\text { Alp } \\
\text { ha }\end{array}$ & 1 & 2 & 3 & 4 & 5 & 6 & 7 & 8 & 9 \\
\hline 1. Performance- & 3.25 & .98 & .81 & -- & & & & & & & & \\
\hline Approach Goals & & & & & & & & & & & & \\
\hline 2. Self-efficacy & 3.99 & .58 & .71 & $.26^{* *}$ & -- & & & & & & & \\
\hline $\begin{array}{l}\text { 3. Task Value- } \\
\text { Utility }\end{array}$ & 4.20 & .71 & .76 & $.24^{* *}$ & $.29^{* *}$ & -- & & & & & & \\
\hline $\begin{array}{l}\text { 4.Performance- } \\
\text { Avoidance Goals }\end{array}$ & 4.09 & .79 & .65 & $.24^{* *}$ & $.23^{* *}$ & $.29^{* *}$ & -- & & & & & \\
\hline $\begin{array}{l}\text { 5. Regulation of } \\
\text { Value and Mastery } \\
\text { Goals }\end{array}$ & 3.73 & .79 & .79 & $.29^{* *}$ & $.39^{* *}$ & $.57^{* *}$ & $.39^{* *}$ & -- & & & & \\
\hline 6. Self-consequating & 3.55 & .95 & .74 & $.26^{* *}$ & $.14^{* *}$ & $.25^{* *}$ & $.25^{* *}$ & $.40^{* *}$ & -- & & & \\
\hline $\begin{array}{l}\text { 7. Regulation of } \\
\text { Situational Interest }\end{array}$ & 2.90 & .95 & .71 & $.27^{* *}$ & $.11^{* *}$ & $.19^{* *}$ & $.16^{* *}$ & $.26^{* *}$ & $.39^{* *}$ & -- & & \\
\hline $\begin{array}{l}\text { 8. Regulation of } \\
\text { Performance- } \\
\text { Avoidance Goals }\end{array}$ & 4.02 & 1.02 & .78 & $.13^{* *}$ & .07 & $.25^{* *}$ & $.38^{* *}$ & $.49^{* *}$ & $.32^{* *}$ & $.15^{* *}$ & -- & \\
\hline $\begin{array}{l}\text { 9. Prior grade reten- } \\
\text { tion }\end{array}$ & 1.31 & .62 & - & $.13^{* *}$ & $.18^{* *}$ & $.15^{* *}$ & $-.19^{* *}$ & $-.19^{* *}$ & -.08 & -.04 & -.06 & -- \\
\hline
\end{tabular}

Motivational regulation strategies. A global evaluation of the means indicated some variability in how often each type of motivational regulation strategy was reported. Tukey HSD post hoc tests indicated significant differences in how often each type of strategy was reported $\left[\mathrm{F}(1,549)=213.75, p<.001, \eta^{2}=.28, \pi=1.00\right]$. The highest mean value corresponded to the regulation of performance-avoidance goals $(M=4.02, S D=1.02)$, whereas the factor with the lowest mean was regulation of situational interest $(M=2.90, S D=0.95)$ (Table 1). The values obtained from correlations between factors indicated weak to moderate correlations $(.15 \leq r \leq .49)$, revealing sensibility of the instrument to various areas within the conceptual field of motivational regulation strategies (Field, 2009). Table 1 shows that the factors are all correlated, with higher correlations between factor 5 and 8 , more specifically, items that assess strategies based on value and mastery and those related to performance $(r=.49, p \leq .01)$ and lower correlation between factors 7 and 8 , regulation of situational interest, and strategies based on reminding performance goals $(r=.15, p \leq .01)$. 


\section{Confirmatory factor analysis}

Confirmatory factor analyses were performed to examine the construct validity of the SRMLS, which refers to the scales ability to actually measure the proposed constructs (Westen \& Rosenthal, 2003).

On studying the factorial structure of the SRMLS, six models were formulated, based on theoretical analysis to identify competing models, compare fit results, and find the most plausible factorial solution (Bentler \& Bonett, 1980; Hoyle \& Panter, 1995).

Regarding motivational beliefs three models were tested: (1) a model where items measured ungrouped beliefs (Model A), (2) a solution where items measured independent factors for motivation beliefs (Model B), and (3) a second-order final model where items measure a common factor that groups all motivation beliefs (Model C). Similar models were analyzed to test SRM strategies: (1) the first model tested an ungrouped solution (Model D), (2) the second factorial model proposed independence among factors (Model E) and (3) the third model analyzed a higher order solution that reconciles all motivation strategies (Model F).

More specifically, Models A and D tested if motivational personal variables (performance-approach goals, self-efficacy, task value and performance-avoidance goals), and the regulation of motivation strategies (regulation of value and mastery goals, self-consequating, regulation of situational interest, regulation of performance-avoidance goals) could not be inferred by the participants' responses. Models B and E assume an independent-factor solution with items being grouped into the above latent variables. Finally, Models $\mathrm{C}$ and $\mathrm{F}$ propose a higher-order structure representing the common variance of the given latent factors. The variance of all latent variables, as well as the correlation between each pair of factors, were constrained to 1.0 .

Maximum likelihood estimation was used to test the formulated factorial models. Evaluation of the model fit was based on the following fit indices: chi-square, root mean square error of approximation (RMSEA), normed fit index (NFI), comparative fit index (CFI), Goodness of Fit Index (GFI), Incremental Fit Index (IFI), Tucker-Lewis index (TLI) and Akaike Information Criterion (AIC). The fit of a model was considered to be acceptable 
when NFI, CFI, GFI and IFI values are close to 1(Bentler, 1990). A RMSEA value equal to (or less than) .08 indicates a good fit (Browne \& Cudeck, 1993). Concerning AIC, the model with the lowest value has the best fitting (Schermelleh-Engel, Moosbrugger, \& Müller, 2003).

Motivational beliefs scale. Confirmatory factor analysis showed that the best fitting model was the common factor one (Model C), $\chi^{2}(73, \mathrm{~N}=550)=259,71, p<.001$, RMSEA $=.068, \mathrm{NFI}=.882, \mathrm{CFI}=.912$, and $\mathrm{IFI}=.913$. Despite theoretical considerations regarding the importance of testing alternative models consisting of ungrouped items and independent factors (Colquitt, 2001), Models A and B were rejected since their fit indexes were not adequate. Figure 1 shows that the standardized latent variables factor loadings range between 0.51 and 1.07. The former corresponded to item A4 of the performance-avoidance goals factor, and the latter to the item A7 of the performance-approach goals factor. All factor loadings of the observed variables were above 0.4 and statistically significant, indicating that latent variables are being adequately measured (Gau \& Hung, 2014).

Motivational regulation strategies scale. For this scale, Model E representing the independent factor structure was the one with better fit. For this solution, confirmatory factor analysis revealed the given fit indexes: $\chi 2(59, \mathrm{~N}=550)=234.79, p<.001$, RMSEA $=.074$, NFI $=.900$, CFI $=.923$, and IFI $=.923$ (see Table 2). As mentioned previously, alternative models consisting of ungrouped items and higher order factors (Colquitt, 2001) were tested, and rejected because of their inadequate fit indexes. The independent factor model fit the data relatively well, with a slight improvement over fit results. Table 2 shows that the standardized latent variables factor loadings range between 0.64 and 1.44. The lowest value corresponds to item D7 of the regulation of value and mastery goals factor, and the highest one to item D16 of the regulation of situational interest factor. Because values were above 0.4 , it can be assumed that latent variables are being adequately measured (Gau \& Hung, 2014). Correlation coefficients between the four latent variables ranged between .12 and .47 (Figure 1), indicating positive, yet weak correlations, suggesting that distinct dimensions are being measured. 

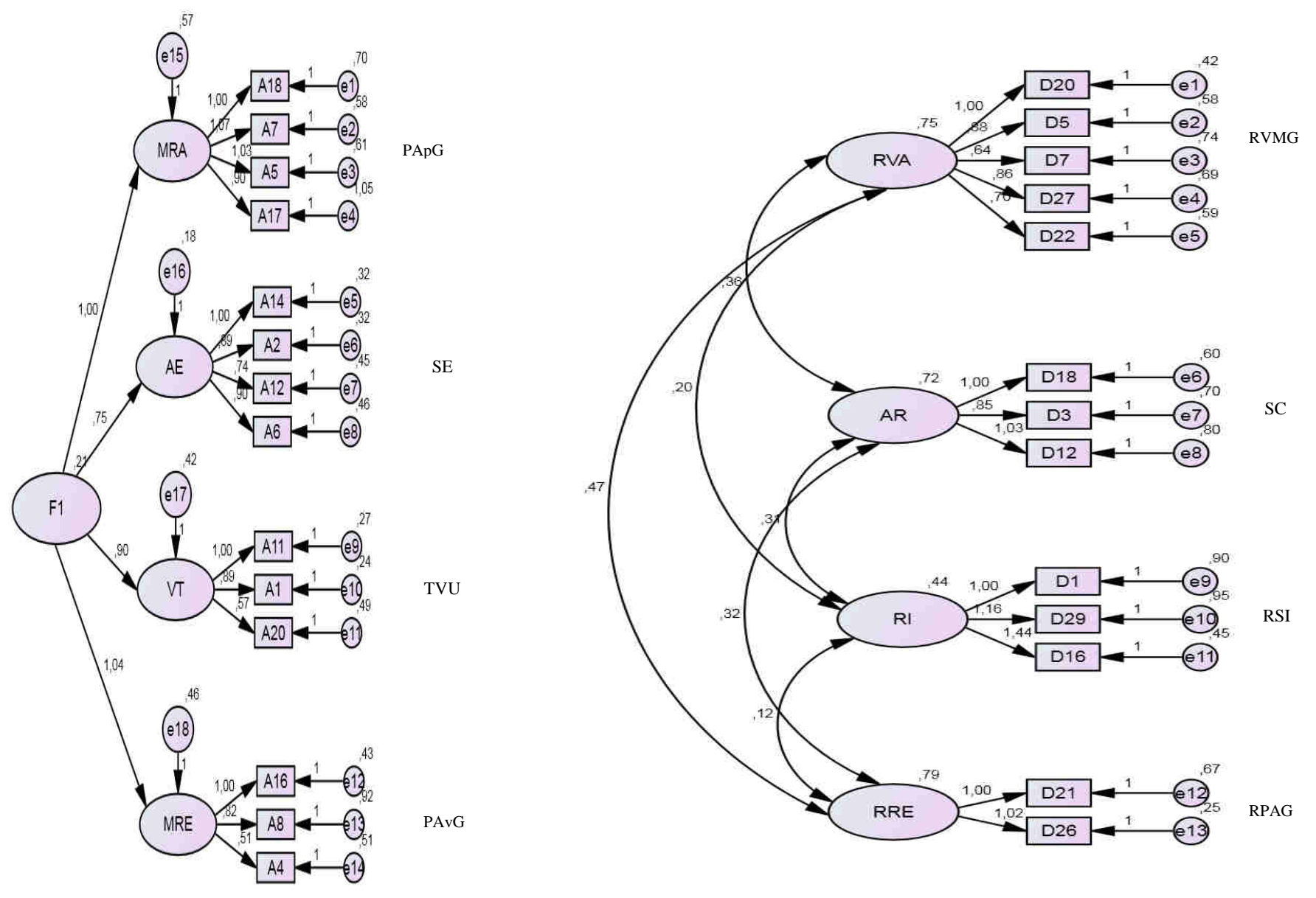

Figure 1. Result of confirmatory analysis.

Motivational beliefs. Performance-Approach Goals (PApG); Self-efficacy (SE); Task Value-Utility (TVU);

Performance-Avoidance Goals (PAvG). Regulation of motivation strategies. Regulation of Value and Mastery

Goals (RVMG); Self-consequating (SC); Regulation of Situational Interest (RSI); Regulation of Performance-

Avoidance Goals (RPAG) 
Table 2. Fit indices for the confirmatory factor analysis

\begin{tabular}{lllllllll}
\hline & $\chi^{2}$ & df & $\chi^{2} / \mathbf{d f}$ & IFI & CFI & GFI & RMSEA & AIC \\
\hline MA & 1160.81 & 77 & 15.01 & .491 & .488 & .730 & .160 & 1216.81 \\
MB & 257.57 & 71 & 3.63 & .913 & .912 & .937 & .069 & 325.57 \\
MC & 259.71 & 73 & 3.56 & .913 & .912 & .936 & .068 & 323.71 \\
MD & 909.05 & 65 & 13.98 & .631 & .629 & .773 & .154 & 961.05 \\
ME & 234.79 & 59 & 3.98 & .923 & .923 & .935 & .074 & 298.79 \\
MF & 282.15 & 61 & 4.63 & .903 & .903 & .924 & .081 & 342.15 \\
\hline
\end{tabular}

MA: items measure ungrouped beliefs

MB: items measure independent factors for motivation beliefs

MC: items measure a common factor that groups all the motivation beliefs

MD: items measure ungrouped strategies

ME: items measure independent factors for strategies

MF: items measure a common factor that groups all the motivation strategies

\section{Concurrent validity}

The concurrent validity of this dimension of the instrument was analyzed with the correlation between the data obtained with this new instrument and responses to other scales that had already been validated, namely the PALS and the MSPE, which measure the same constructs. Since there are no known validated instruments for the Portuguese population to evaluate all variables, only achievement goals and self-efficacy expectations were studied. The results indicate significant positive correlations between these scales and the new instrument. More specifically, between performance goals and factors that evaluate the performance-avoidance goals $(r=.26, p \leq .01)$ and performance- approach goals $(r=.69, p \leq .01)$, and between self-efficacy and MSPE scale $(r=.56, p \leq .01)$.

Aside from the aforementioned analysis, concurrent validity was also studied using a performance criterion. Based on theoretical and research arguments, achievement goal orientation, task value and self-efficacy should be strongly associated with students' achievement (Eccles \& Wigfield, 2002; Velayutham, Aldrige \& Fraser, 2011). Thus, students' prior grade retentions (provided by participants at the time the scales were administered) were used as an indicator of school achievement.

Following the hypothesis that there is a negative correlation between the various beliefs and previous grade retentions, Pearson coefficients were computed. Data analysis indi- 
cated significant and negative correlations $(p \leq .001)$ between the number of previous grade retentions and all motivational beliefs studied $(-.13 \leq r \leq-.19)$.

Also based on theoretical and research arguments, motivational regulation strategies should be associated with students' achievement (Gonzalez et al., 2005; Wolters, 1999, 2011; Wolters \& Benzon, 2010). Thus, students' prior grade retentions were used as an indicator of school achievement. Pearson coefficients were performed according to the hypothesis that there was a negative correlation between the various strategies and previous grade retentions. Data analysis indicated only one significant and negative correlation between the number of previous grade retentions and the regulation of value and mastery goals $(r=-.19 ; p<.01)$.

\section{Discussion and Conclusions}

The purpose of this investigation was to identify factors that may contribute to students's self-regulation of motivation to learn. More specifically, our aim was to study self variables that might promote one'regulation of motivation for learning. A new instrument called Self-Regulation of Motivation for Learning Scales (SRMLS) which assesses motivational beliefs and motivational regulation strategies was used. Also, this study contributes to further develop SRMLS. Several analyses, to examine the validity and reliability of the developed instrument in our sample were conducted. Findings supported good psychometric properties of the two dimensions/scales - motivational beliefs, and motivational regulation strategies. A confirmatory factor analysis was performed to assess the construct validity of the instrument. Moreover, concurrent validity was also assured. The sub-areas from each scale revealed good values of internal reliability.

Regarding the study of the SRMLS dimensions, means analyses showed task value beliefs to be the most frequently reported, suggesting a greater importance attributed by students to the value and utility of school contents and tasks. This result is coherent with research highlighting the relevant role of school task value beliefs in structuring students' motivation to learn (Eccles \& Wigfield, 2002; Pintrich \& De Groot, 1990; Wolters, Yu, \& Pintrich, 1996; Wolters \& Rosenthal, 2000; Wolters \& Benzon, 2010). Furthermore, empirical research in this field has constantly found a relation between students' value for the material they are 
learning, and their behavior -namely through the use of cognitive and self-regulatory strategies (Pintrich \& DeGroot, 1990; Wolters \& Pintrich, 1998).

Performance-approach goals were less mentioned by the students. It is important to consider that performance goals have been conceptualised in both approach (aiming to demonstrate high levels of skills relative to others), and avoidance perspectives (avoiding the demonstration of the lack of skills) (Elliot, 1997, 1999). For the development of those items, we assumed that students pursuing performance goals intended to demonstrate competence, and were focused on extrinsic variables including gaining appreciation and pleasing others (Ames, 1992).

However, this conceptualisation might not be straightforward. Several authors have claimed that students who wish to demonstrate high performance do not necessarily do so by comparing themselves with others, which might explain the lowest means in this sample (Dowson \& McInerney, 2003). Brophy (2005) suggested that students rarely describe performance goals with social comparison as being relevant to their achievement. In a focus group study with adolescents, Mansfield (2012) found that performance-grade goals (i.e. the desire to attain a particular standard of achievement that will lead to other things, such as future success or social approval) are most commonly articulated, than those from social comparison. Additionally, performance goals without social comparison have been found in other studies (for example, Dowson \& McInerney, 2003). Such findings might indicate that there are other school variables, such as national curriculum, reporting procedures, and/or cultural contexts that influence performance goals. In addition, achievement goals, as classically defined, may not reflect all of the adolescents' reasons for achieving in school.

Also, regarding performance goals, results showed a weak correlation between performance-avoidance goals and self-efficacy beliefs, which is consistent with previous work (e.g., Elliott \& Dweck 1988). Schunk and Zimmerman (1994) discussed how self-efficacy could be influenced by learning and performance goal types, and claimed that self-efficacy should be higher under learning than under performance goals. Other studies have verified that when perceptions of competence are high, the positive possibility of success is mostly relevant, whereas when perceptions of competence are low, the negative possibility of failure 
is particularly salient (Elliot \& Church, 1997). More recently, Law, Elliot and Murayama (2012) suggested that when perceived competence is high, individuals can pursue performance-approach goals without necessarily pursuing performance-avoidance goals. Nonetheless, when perceived competence is low, individuals are likely to pursue performanceapproach and performance-avoidance goals simultaneously.

Concerning the achievement goals results, students' answers emphasized performance avoidance goals rather than performance-approach goals. Similar results were found in an exploratory analysis of the instrument (Authors, in press-a), and in another national study (Paixão \& Borges, 2005), which might support a cultural justification for these differences. Therefore, apart from the approach or avoidance nature of the goals, Portuguese students seem to be more focused on this type of target, rather than on mastery goals.

These findings deserve special attention in terms of educational intervention, since the literature highlights the positive contribution of learning goals for academic success (e.g., Linnenbrink \& Pintrinch, 2002). It is crucial to explore this result in future research, in students' and teachers' conceptions about achievement goals, and their effects on motivation and learning. Qualitative studies conducted by interviews or focus groups might offer a more comprehensive understanding of this issue.

The strategy most consistently reported was the regulation of performance goals, which follows previous studies (Wolters, 1999; Wolters \& Benzon, 2010). However, in this study, it concerns a specific dimension of performance goals which is avoidance. This implies that students reported that they would remind themselves about their desire to avoid getting poor grades as a way of getting themselves to continue working on school assignments more often than any of the other strategies assessed. Also, performance-avoidance goals were the beliefs most often reported by students, as discussed earlier. The combination of such results suggests a pattern in students' answers about their beliefs, values and goals, as well as the strategies they believe to be useful for self-regulation of motivation.

The regulation of situational interest seems to be the least effective strategy in students' perspective. This result was also found in previous studies, indicating that students 
were less likely to report that they would try to increase their motivation by making the task more pleasurable or interesting (Wolters, 1999; Wolters \& Benzon, 2010).

The confirmatory factor analysis supports the adequacy of a global factor concerning all of the motivation beliefs in study, suggesting a general motivational orientation for achievement. Therefore, current findings may disclose future avenues of research on achievement goal theory (Ames, 1992; Dweck \& Legget, 1988), and expectancy-value theory (Eccles, 2009; Eccles et al., 1983; Wigfield \&Eccles, 2000). There is a vast body of literature that addresses the effort of understanding how these motivational beliefs are related and affect various outcomes. Although several studies indicate strong correlations between two or more of these motivation determinants (e.g., Bong, 2009; Bong et al., 2013; Hulleman et al., 2008; Lee et al., 2014; Murayama et al., 2011), we could not find studies that suggested a global motivation orientation regarding school engagement. Exploring a common factor that organizes motivation beliefs is not only interesting in order to articulate the existing theories of motivation, but it may also be fundamental to understand students' motivational dynamics. Further research is needed to support these results and explore the empirical, theoretical and methodological adequacy of such proposal.

Concerning the motivational regulation strategies, the analyses supported the factorial validity of the first order structure of the SRMLS. Such finding is consistent with previous studies (Gonzalez et al., 2005), and suggests that students' self-regulation of motivational strategies revealed a multidimensional construct. Students may choose from a variety of strategies to regulate their motivation in a particular situation. Moreover, students with high selfregulation competences might choose appropriate combinations of strategies to achieve success in any given school task, and can change their choice over time and across subjects as necessary. On the other hand, less capable students may only be able to access one or two strategies, which may be less effective in certain situations. One important implication of SRM multidimensionality is to highlight the importance of teachers developing instructional practices based on the self-regulation of motivation by introducing students to a range of strategies, from which they may choose to suit them to the task (Gonzalez et al., 2005). 
It is important to discuss several limitations of this study. More specifically, it is a correlational study that was conducted among students attending $7^{\text {th }}$ through 9 th school grades, within a particular cultural context, and regarding all school subjects, which requires caution in generalizing its findings to students of other grades, contents and cultures. Furthermore, current findings and interpretations are limited to the motivational beliefs and strategies here considered as indicators of students' motivational orientation for learning. Therefore, future research could explore the role of other variables, such as outcome expectations on motivation for achievement (Velayutham et al., 2011; Wolters, 2011). Moreover, items related to the regulation of mastery goals were removed from the factorial structure for statistical reasons, as mentioned above. Considering the importance of such goals in the context of self-regulated learning and motivation, further work should explore this result with other samples.

Although the validity of the scales presented here was corroborated by quantitative analysis, these results could be enriched by further qualitative methods, such as case studies, interviews with teachers and students, classroom observations, among others. These scales provide correlational information, and therefore, for in-depth knowledge of the self-regulation of motivation process, experimental and longitudinal studies should be considered. Finally, the variable used to assess school success (i.e. prior grade retention) may not have been a strong indicator of competence regarding self-regulated learning and/or of successful learning.

In spite of such constraints, the present study also makes a contribution for the development of an instrument that could be used to assess students' achievement goals, selfefficacy expectations, and task value beliefs, as well as several motivational regulation strategies, which together contribute towards more effective learning. We can consider that SRMLS provides coherent results about students' motivational processes, and a set of different strategies that students from different ages and grades may use to regulate motivation, within the context of self-regulated learning (Wolters, 1999, 2011).

This tool can be important for teachers and researchers as it provides information regarding crucial aspects of students' motivation for achievement. For teachers, it is an easy way to collect data about students' motivation which may influence educational practices. For researchers, this instrument can contribute to a broader understanding of the processes involved in the self-regulation of motivation. Also, this instrument might be valuable for the 
evaluation of intervention programs aimed at promoting more adaptive motivational beliefs about school, namely self-efficacy, task value and achievement goals.

Concerning our primary goal, results showed that motivational beliefs such as task value, self-efficacy expectations and achievement goals are good predictors of SRM strategies. As so, results suggest that enhancing students'self-efficacy, promoting positive beliefs about school value and helping the development of achievement goals, can have a high impact on students' motivation.

\section{References}

Alderman, M. K. (2004). Motivation for achievement: possibilities for teaching and learning. Mahwah NJ: Lawrence Erlbaum.

Ames, C. (1992). Classrooms: Goals, structures, and student motivation. Journal of Educational Psychology, 84(3), 261-271.

Bandura, A. (1986). Social foundations of though and action. Englewood Cliffs, New Jersey: Prentice Hall.

Bandura, A. (1990). Multidimensional scales of perceived academic efficacy. Stanford University, Stanford, CA.

Bennett, D. A. (2001). How can I deal with missing data in my study? Australian and New Zealand Journal of Public Health, 25(5), 464-469.

Bentler, P. M. (1990). Comparative fit indexes in structural models. Psychological Bulletin, 107(2), 238-246.

Bentler, P. M., \& Bonett, D. G. (1980). Significance tests and goodness of fit in the analysis of covariance structures. Psychological Bulletin, 88, $588-606$.

Boekaerts, M. (2002). Motivation to Learn. In H. Walberg (Ed.) Educational Practices Series. International Academy of Education-International Bureau of Education (UNESCO).

Boekaerts, M., \& Corno, L. (2005). Self-regulation in the classroom: A perspective on assessment and intervention. Applied Psychology: An International Review, 54(2), 199231. 
Bong, M. (2009). Age-related differences in achievement goal differentiation. Journal of Educational Psychology,101, 879-896.

Bong, M., Woo, Y., \& Shin, J. (2013). Do students distinguish between different types of performance goals? Journal of Experimental Education, 81, 464-489.

Brickman, S., \& Miller, R. B. (2001). The impact of sociocultural knowledge on perceptions of the future and self-regulation. In D. M. McInerney \& S. Van Etten (Eds.), Research on Sociocultural Influences on Motivation and Learning. Greenwich, CT: Information Age Publishing.

Brophy, J. (2005). Goal theorists should move on from performance goals. Educational Psychologist, 40(3), 167-176.

Browne, M. W., \& Cudeck, R. (1993). Alternative ways of assessing model fit. In K. A. Bollen \& J. S. Long (Eds.), Testing structural equation models (pp. 136-162). Newbury Park, CA: Sage.

Byrne, B. M. (2010). Structural equation modeling with AMOS: Basic concepts, applications, and programming (2nd ed.). Mahwah, NJ: Erlbaum

Colquitt, J. A. (2001). On the dimensionality of organizational justice: a construct validation of a measure. Journal Applied Psychology, 86, 386-400.

Dowson, M., \& McInerney, D. M. (2003). What do students say about their motivational goals? Towards a more complex and dynamic perspective on student motivation. Contemporary Educational Psychology, 28, 91-113.

Dweck, C. S., \& Leggett, E. L. (1988). A social-cognitive approach to motivation and personality. Psychological Review, 95, 256-273.

Dweck, C. S., \& Master, A. (2007). Self-theories motivate self-regulated learning. In D. H. Schunk \& B. Zimmerman (Eds.), Motivation and Self-Regulated Learning: Theory, Research, and Applications (pp. 31-51). Mahwah, NJ: Erlbaum.

Eccles, J. (2009) Who Am I and what Am I going to do with my life? Personal and Collective Identities as Motivators of Action, Educational Psychologist, 44(2), 78-89, doi: $10.1080 / 00461520902832368$

Eccles, J. S., Adler, T. F., Futterman, R., Goff, S. B., Kaczala, C. M., Meece, J. L., \& Midgley, C. (1983). Expectancies, values and academic behaviors. In J T. Spence (ED.), Achievement and Achievement Motivation (pp.75-146). San Francisco, CA: W.H. Freeman. 
Eccles, J. S., \& Wigfield, A. (2002). Motivational beliefs, values, and goals. Annual Review of Psychology, 53, 109-132.

Elliot, A. J. (1997). Integrating the "classic" and "contemporary" approaches to Achievement motivation: A hierarchical model of approach and avoidance achievement motivation. In M.L. Maehr \& P.R. Pintrich (Eds.), Advances in Motivation and achievement (Vol. 10, pp. 143-179). New York: JAI Press.

Elliot, A. J. (1999). Approach and avoidance motivation and achievement goals. Educational Psychologist, 34(3), 169-189.

Elliot, E. S., \& Church, M. A. (1997). A hierarchical model of approach and avoidance achievement motivation. Journal of Personality and Social Psychology, 72, 218-232.

Elliott, E. S., \& Dweck, C. S. (1988). Goals: An approach to motivation and achievement. Journal of Personality and Social Psychology, 54, 5-12.

Field, A. (2009). Discovering Statistics Using SPSS (and sex and drugs and rock ' $n$ ' roll) (3rd edition). London: Sage.

Fryer, J. W., \& Elliot, A. J. (2007). Self-regulation of achievement goal pursuit. In D. Schunk \& B. Zimmerman (Eds.), Motivation and Self-Regulated Learning: Theory, Research, and Applications. (pp. 53-76). Hillsdale, NJ: Lawrence Erlbaum Associates.

Gau, B.S., \& Hung, C. C. (2014). The self-efficacy scale for preschool teachers regarding asthma care: instrument development and validation. Journal of School Health, 84(2), 9198. doi: 10.1111/josh.12122.

Gonzalez, S., Dowson, M. Brickman, S., \& McInerney, D. (2005) Self-regulation of academic motivation: Advances in structure and measurement. Australian Education Index, Australian Center for Educational Research. Sydney, Australia.

Hill, M. M., \& Hill, A. (2009). Investigação por questionário (2nd ed.). Lisboa: Edições Sílabo.

Hoyle, R. H., \& Panter, A. T. (1995). Writing about structural equation models. In R. H. Hoyle (Ed.), Structural equation modeling: Concepts, issues, and applications (pp. 158 176). Thousand Oaks, CA: Sage.

Hulleman, C. S., Durik, A. M., Schweigert, S., \& Harackiewicz, J. M. (2008). Task values, achievement goals, and interest: An integrative analysis. Journal of Educational Psychology, 100, 398-416. 
Law, W., Elliot, A. J., \& Murayama, K. (2012). Perceived competence moderates the relation between performance-approach and performance-avoidance goals. Journal of Educational Psychology, 104, 806-819.

Lee, J., Bong, M., \& Kim, S. (2014). Interaction between task values and self-efficacy on maladaptive achievement strategy use. Educational Psychology, 34, 538-560.

Linnenbrink, E. A., \& Pintrich, P. R. (2002). Motivation as an enabler for academic success. School Psychology Review, 31(3), 313-327.

Mansfield, C. (2012). Rethinking motivation goals for adolescents: Beyond achievement goals. AppliedPsychology, 61(4), 564-584.

Midgley, C., Maehr, M., Hruda, 1., Anderman, E., Anderman, K., Freeman, M., Gheen, M., Kaplan, A., Kumar, R., Middleton, M., Nelson, J., Roeser, R., \&Urdan, T. (2000). Manual for the Patterns of Adaptive Learning Scales. Ann Arbor, MI: University of Michigan.

Montalvo, F., \& Torres, M. (2004). Self-regulated learning: Current and future Directions. Electronic Journal of Research in Education Psychology, 2(1), 1696-2095.

Murayama, K., Elliot, A.J., \& Yamagata, S. (2011). Separation of performance-approach and performance-avoidance achievement goals: A broader analysis. Journal of Educational Psychology, 103, 238-256.

Paixão, M. P., \& Borges, G. (2005). O papel do tipo de orientação para objectivos no desenvolvimento da identidade vocacional: estudo exploratório com alunos do $9^{\circ}$ ano de escolaridade (The role played by goal orientation in the development of vocational identity: $\mathrm{Na}$ exploratory study with 9th grade students). Revista Portuguesa de Psicologia, 38, 133153.

Pajares, F. (2007). Motivation role of self-efficacy beliefs in self-regulated learning. In D. Schunk \& B. Zimmerman (Eds.), Motivation and Self-Regulated Learning: Theory, Research, and Applications (pp. 53-76). Hillsdale, NJ: Lawrence Erlbaum Associates.

Pintrich, P.R. (1999). The role of motivation in promoting and sustaining self-regulated learning. International Journal of Educational Research, 31, 459-470.

Pintrich, P. R. (2003). A motivational science perspective on the role of student motivation in learning and teaching contexts. Journal of Educational Psychology, 95, 667-686.

Pintrich, P. R., \& de Groot, E. V. (1990). Motivational and self-regulated learning components of classroom academic performance. Journal of Educational Psychology, 82, 33 40. 
Purdie, N., \& Hattie, J. A. (1996). Cultural differences in the use of strategies for selfregulated learning. American Educational Research Journal, 33,845-871.

Sansone, C. \&Thoman (2005). Interest as the missing motivator in self-regulation. European Psychologist, 10, 175-186.

Sansone, C., Weir, C., Harpster, L., \& Morgan, C. (1992). Once a boring task always a boring task? : Interest as a self-regulatory mechanism. Journal of Personality and Social Psychology, 63, 379-390.

Sansone, C., Wiebe, D. J., \& Morgan, C. L. (1999). Self-regulating motivation: The moderating role of hardiness and conscientiousness. Journal of Personality, 67, 701-733.

Schafer, J. L. (1999). Multiple imputation: a primer. Stat Methods in Med, 8(1), 3-15.

Schermelleh-Engel, K., Moosbrugger, H. \& Müller, H. (2003). Evaluating the fit of structural equation models: Tests of significance and descriptive goodness-of-fit measures. MPRonline, 8(2), 23-74.

Schunk, D. H. (2004). Learning theories: An educational perspective. Upper Saddle River, NJ: Pearson.

Schunk, D. H., \& Zimmerman, B. J. (1994). Self-regulation of learning and performance: Issues and educational applications. Hillsdale, NJ: Erlbaum.

Teixeira, M. O. (2008). A escala multidimensional de auto-eficácia percebida: Um estudo exploratório numa amostra de estudantes do ensino superior (The multidimensional scale of perceived self-efficacy: An exploratory study of a sample of higher education students). Revista Iberoamericana de Diagnóstico y Evaluación Psicológica, 25, 141-157.

Velayutham, S., Aldridge, J. M., \& Fraser, B. J. (2011). Development and validation of an instrument to measure students' motivation and self-regulation in science learning. International Journal of Science Education, 33(15), 2159-2179.

Westen, D., \& Rosenthal, R. (2003). Quantifying construct validity: Two simple measures. Journal of Personality and Social Psychology, 84(3), 608-618.

Wigfield, A., \& Eccles, J. S. (2000). Expectancy-value theory of achievement motivation. Contemporary Educational Psychology, 25, 68-81.

Wolters, C. (1998). Self-regulated learning and college students' regulation of motivation. Journal of Educational Psychology, 90(2), 224-235. 
Wolters, C. (1999). The relation between High School students' motivational regulation and their use of learning strategies, effort, and classroom performance. Learning and Individual Differences, 11, 281-299.

Wolters, C. (2003). Regulation of motivation: Evaluating an underemphasized aspect of selfregulation learning. Education Psychologist, 38(4), 189-205.

Wolters, C. (2011). Regulation of motivation: Contextual and social aspects. Teacher's College Record, 113(2), 265-283.

Wolters, C., \& Benzon, M. (2010, September). Understanding and predicting the selfregulation of motivation in college students. Paper presented at the 11th International Conference on Education Research, Seoul, Korea.

Wolters, C., Benzon, M., \& Arroyo-Giner, C. (2011). Assessing strategies for the selfregulation of motivation. In D. Schunk \& B. Zimmerman (Eds.), Handbook of selfregulation of learning and performance (pp. 298 - 312). New York: Routledge.

Wolters, C., \& Pintrich, P. R. (1998). Contextual differences in student motivation and selfregulated learning in mathematics, english, and social studies classrooms. Instructional Science, 26, 27-47.

Wolters, C., \& Rosenthal, H. (2000). The relation between students' motivational beliefs and their use of motivational regulation strategies. International Journal of Educational Research, 33(7-8), 801-820.

Wolters, C., Yu, S., \& Pintrich, P.R. (1996). The relation between goal orientation and students' motivational beliefs and self-regulated learning. Learning and Individual Differences, 8, 211-238.

Xu, J., \& Corno, L. (1998). Case studies of families doing third-grade homework. Teachers College Record, 100, 402-436.

Zimmerman, B. (2008). Investigating self-regulation and motivation: Historical background, methodological developments, and future prospects. American Educational Research Journal, 45(1), 166-183.

Zimmerman, B. (2011). Motivational sources and outcomes of self-regulated learning and performance. In Zimmerman, B. J., \& Schunk, D. H. (Eds.). Handbook of self-regulation of learning and performance (pp. 49-64). New York: Routledge.

Zimmerman, B. J., \& Bandura, A. (1994). Impact of self-regulatory influences on writing course attainment. American Educational Research Journal, 31, 845-862. 
Zimmerman, B., \& Martinez-Pons, M. (1990). Student differences in self-regulated learning: Relating grade, sex and giftedness to self-efficacy and strategy use. Journal of Educational Psychology, 82(1), 51-59.

Zimmerman, B., \& Schunk, D. (2001). Theories of self-regulated learning and academic achievement: An overview and analysis. In Self-regulated learning and academic achievement (2nd ed.) (pp. 1-37). Mahwah, NJ: Erlbaum.

Zimmerman, B., \& Schunk, D. (2008). Motivation: An essential dimension of self-regulated learning. In D. Schunk \& B. Zimmerman, Motivation and self-regulated learning: Theory, research, and application (pp. 1-30). New York: Lawrence Erlbaum Associates. 


\section{APPENDIX}

Descriptions and Examples of the Variables Used

\begin{tabular}{llll}
\hline Category & Variable & Description & Example \\
\hline Beliefs & Self-efficacy expectations & Beliefs that people have about their educational skills. & $\begin{array}{l}\text { I think I can learn school sub- } \\
\text { jects. }\end{array}$
\end{tabular}

\section{Achievement goals.}

Items measuring achievement goals included three goal types: performance-approach goals; mastery goals; performance-avoidance goals.

Cognitive representations of a future result that a student intends to achieve or avoid. The final state of these goals is the acquisition or the improvement of competence - mastery goals - or the demonstration of competence - performance goals.

Task value

Regulation of mastery goals

Regulation of value

The value that students attribute to school tasks and contents, more specifically, the extent to which they consider them important, interesting and useful for future goals. Student's use of thoughts or self-instructions, to improve understanding, the development of school and academic skills, or to improve performance, according to criteria established by the student.

Self-statements and other strategies aimed to enhance personal relevance of school contents or in carrying out school tasks in order to maintain motivation. These are strategies that students can use to make school assignments more relevant and / or significant (e.g., identifying
Performance - approach: It motivates me to think that I can get better grades than my classmates. Performance avoidance: It worries me having bad grades. Mastery goals: I prefer subjects I like, even if they are more difficult.

The material I learn in school will be useful for me in my future studies.

I tell myself that I must continue to study to learn as much as I can.

I try to convince myself that this subject / task can be useful for me in the future. 
Regulation of situational interest

\section{Regulation of performance goals}

Items measuring these strategies included two regulation strategies types: regulation of performance approach goals and regulation of avoidance performance goals.

\section{Self-consequating}

Environmental structuring personally relevant aspects or usefulness in school subjects and focus on it).

Self-instructional strategies aiming to increase interest / immediate pleasure while performing an activity.

This category concerns the focusing on incentives linked to school results, which encourages students to persist on task when a student is attracted to quit during a study task he may purposely continue to work thinking about getting good grades or to avoid being considered incapable).

The assignment of self-reinforcement through the achievement of particular goals associated with the completion of a task.

Strategies to decrease the possibility of task dropout through the reduction of possible distractions, or the decreasing of its intensity.
To make the task less boring I try to focus on a fun aspect it may have.

Regulation of performance approach goals: I think it's worth struggling if this matter/job counts for evaluation.

Regulation of avoidance performance goals: I think that if I don't work my grades will be injured.

I make a deal with myself that if I can finish some of the work I can do something fun afterwards.

I try not to have distractions around me. 